\title{
From the small screen to the big world: mobile apps for teaching real-world face recognition to children with autism
}

This article was published in the following Dove Press journal:

Advanced Health Care Technologies

23 October 2015

Number of times this article has been viewed
AN Sung
A Bai
JG Bowen
$\mathrm{B} \times \mathrm{u}$
LM Bartlett
JC Sanchez
MD Chin
LJ Poirier
MR Blinkhorn
AC Campbell
JW Tanaka

Centre for Autism, Research, Technology and Education (CARTE), Department of Psychology, University of Victoria,Victoria, BC, Canada
Correspondence: James Tanaka

Centre for Autism Research, Technology and Education, Department of Psychology, University of Victoria, Victoria, BC, V8W 2Y2, Canada

Email jtanaka@uvic.ca

\begin{abstract}
In their everyday situations, individuals with autism spectrum disorder (ASD) encounter problems perceiving and understanding the facial expressions of others. If people with ASD have difficulties interpreting facial emotions, it is not surprising that they would struggle in their daily social interactions. An important question is whether facial emotion skills can be learned through systematic instruction and training. The accessibility, portability, and engagement of mobile devices (ie, smartphones, tablets) afford exciting new opportunities for creating innovative apps in emotional face training. In this article, we review the current crop of facial emotion apps for autism. We evaluate the apps according to the following criteria: face-processing skills, social attributes, and usability. We discuss the key ingredients of faceprocessing apps that will help a person on the autism spectrum make the transition from the small screen of the mobile device to the big world of real life.
\end{abstract}

Keywords: mobile apps, emotion, facial expression, development, social skills, gamification

\section{Introduction}

The human face is the gateway to our social world, revealing to others our momentary thoughts, feelings, and intentions. Although most of us can interpret facial cues in an instant, people with autism spectrum disorder (ASD) struggle to perceive facial emotions and interpret the social cues conveyed by the face. An important question is whether the skills required to read the social cues of a face can be learned through systematic instruction and training. Mobile devices (eg, smartphones, tablets) with their flexibility, adaptability, and customizability are promising tools for teaching the social skills involved in face processing. For autism software developers, it is essential that the social skills learned on the small screen of a mobile device transfer to the big world of real life. In our review, we begin by discussing the social consequences of face-processing deficits in ASD. We then examine the potential of mobile devices for promoting face-processing skills and provide a systematic review of current mobile apps that are intended to improve face-processing abilities. Finally, we discuss exciting new innovations that will help children on the autism spectrum make the transition from the small screen to the big world.

\section{Challenge: improving social communication in autism through face processing}

The most recent statistics show that approximately one of every 68 children in the United States are diagnosed with ASD. ${ }^{1}$ According to the fifth edition of the Diagnostic and Statistical Manual of Mental Disorders, individuals with ASD show repetitive 
patterns of behavior, display restricted interests, and have difficulties interacting with others in a social context. ${ }^{2}$ Although not a core symptom of the autism diagnosis, many children with ASD are impaired in their ability to recognize facial identity ${ }^{3}$ and facial emotion. ${ }^{4}$ Studies have shown that persons with ASD are delayed in attending to faces ${ }^{5-7}$ and have difficulty recognizing facial identities ${ }^{8-10}$ and interpreting facial expressions. ${ }^{11-13}$ Additionally, individuals on the autism spectrum show deficits in their ability to maintain eye contact and follow the eye gaze of others. ${ }^{14-16}$

Difficulty in perceiving and understanding facial cues in eye contact, gaze, and expression can lead to severe problems in everyday social interactions. For example, people who experience problems in their face-processing abilities are found to rank higher in social anxiety ${ }^{17}$ and along the autism phenotype. ${ }^{18-20}$ Face-processing deficits correlate with social communication impairments in coordinating social attention, ${ }^{21-23}$ language development, ${ }^{24-26}$ understanding the thoughts of others, ${ }^{18,27,28}$ and displaying empathy with others. ${ }^{29,30}$

Atypical patterns in face-processing strategies that are evident in the first and second years of life can produce a cascade of social difficulties later on in childhood, adolescence, and adulthood. Young children on the autism spectrum have problems initiating play with others and show an impaired ability in maintaining peer friendships. ${ }^{31,32}$ For adolescents with ASD, social communication challenges usually intensify as teen relationships take on greater social importance. ${ }^{33}$ Although individuals with ASD may desire greater social interaction, ${ }^{34}$ they experience greater loneliness, social rejection, and bullying than their peers. ${ }^{32,35-37}$ For adults with autism, persistent social communication deficits are evident in their workforce participation. ${ }^{38,39}$ While adults with ASD have little difficulty completing job-related tasks, navigating the social aspect of the workplace proves overwhelming for many people with ASD. ${ }^{40}$ Unfortunately, the evidence suggests that face and social communication abilities of children with ASD do not improve over the course of development $^{41}$ and may persist over the lifespan. ${ }^{42,43}$

\section{Technology, autism intervention, and mobile devices}

Computer-based technologies are promising tools for improving the social communication skills of individuals with ASD. For example, several computerized training platforms have been developed to teach face recognition abilities to individuals with ASD. ${ }^{44}$ Al Alhough positive training effects were obtained in a laboratory context, the real test of these interventions is whether the results transfer to improved social communication in the child's everyday life. ${ }^{47}$ The generalization of face-processing skills from the small screen to the big world is paramount in training social communication skills in ASD. Paradoxically, spending too much time in front of computers has negative effects on the quality of real-life social interactions in typically developing children. ${ }^{48}$

The advent of smart mobile devices provides new learning opportunities for children with ASD, especially in the training of social interaction and communication skills. There are a number of advantages of using mobile devices as assistive tools. First, smartphones and tablets are easy and intuitive to use. On a touch screen, the user can launch programs and access program functions with a simple finger tap or swipe; tactile motor actions are more direct than the mouse and trackpad actions required for desktop and laptop computer programs. More generally, touch screen devices follow the principles of universal design that stress the importance of making technological devices assessable to populations with intellectual disabilities and sensory motor challenges. ${ }^{49}$ Second, mobile apps are well suited to the learning needs of the individuals with ASD because they are visually engaging and provide a consistent, predictable learning environment. ${ }^{50-53}$ Finally, mobile devices are portable. Desktop computers, although suited to deliver facial recognition programs, are stationary and socially isolating, while mobile devices can fit into any individual's pocket and be used anywhere and at any time. Children with ASD can readily carry these devices and use them in everyday situations, including the moments promoting real-life social interactions with their peers. Mobile devices create new options and opportunities for programmers to create innovative instructional content that is appropriate for a diverse group of learners and diverse learning styles. ${ }^{54}$

\section{What makes an effective learning app?}

Training or assistive apps will not be effective if the program is cumbersome to use or is not engaging to the user. An app may have been developed with a valid theoretical rationale and yet still fail to deliver any benefits due to a poor implementation. Usability is a critical design factor for the success of tablet-based mobile apps. According to the International Standards Organization, usability is the extent to which a product can be used by the specified users to achieve specified goals with effectiveness, efficiency, and satisfaction in a specified context of use. ${ }^{55}$ An app is effective if users can complete the target tasks in the manner in which 
they were intended. Users may spend a great deal of time on an app, but if they are not performing the critical tasks or if they are performing them incorrectly, then the app will not be effective in achieving its goal.

There are several approaches for evaluating the usability of an app. One approach is to empirically evaluate the app's effectiveness through user testing. Following this method, naïve users are asked to perform set functions on the app, while an evaluator records his/her errors and problems and afterward, interviews the users about their opinions and impressions of the app. Following a heuristic evaluation approach, an independent evaluator assesses the effectiveness and quality of a program according to established indices of usability, such as ease of use, number of errors, and the cognitive load of the user. ${ }^{56}$ Finally, apps can be assessed with respect to their gamification qualities, such as their use of graphics and sounds; design elements such as interface, levels, and badges; and game-mechanics such as time constraints, limited resources, and special powers. The immense popularity of app games such as Candy Crush or Angry Birds demonstrates the efficacy of game design principles for sustaining a user's interest over a long period of time. It is essential that gaming features are incorporated into the development of academic and social apps because these abilities require weeks, months and if not years to acquire. ${ }^{57}$ A recent meta-analysis indicates that gamification techniques are effective in a wide variety of learning contexts and can produce positive psychological, educational, and behavioral outcomes. ${ }^{58}$ Serious games are designed to promote learning of specific life and academic skills that are particularly challenging and less rewarding for participants. In contrast to nonserious games, the central goal of serious games is that game learning will translate to improved real-life outcomes. ${ }^{59}$ In autism intervention, gamification and serious games provide the key guidelines for creating better learning outcomes for the child in a social skill that will improve his/her everyday life.

\section{A survey of mobile apps in autism face training}

Computer developers with a keen interest in autism intervention have recognized the tremendous potential of mobile devices as powerful instructional tools. The result is that the market has been flooded with autism-aimed apps of varying qualities. Many of these apps are costly, so it is important to establish which apps are worthwhile investments for parents and educators. To this end, we present a review of apps targeting face-processing skills in children with ASD.

The search for apps related to face processing in autism was conducted between March 12 and March 26, 2015, and utilized the Apple store, the Windows store, and the Google Play store. Search terms were autism, ASD, faces, emotion, face affect, and recognition. Such search terms were chosen to identify apps specifically designed for individuals on the autism spectrum as well as apps focusing on faces, emotions, face affect, and face recognition, and to exclude apps focusing on feelings, behavior regulation, self-monitoring, and emotional regulation.

Exclusion criteria covered: 1) apps that focused on domains other than face processing (eg, identifying internal emotions in social situations with social stories); 2) apps that focused on a single emotion; 3 ) apps that focused on body language, such as hand gestures; 4) duplicates or older versions of apps; 5) apps without gamification aspects; and 6) apps that relied solely on computer-generated avatars rather than photographs of real people. The primary survey returned hundreds of autism-related apps, but the exclusion criteria removed the majority. The final survey contained 13 apps that met the inclusion criteria.

Each app was evaluated with respect to: 1) face-processing skills; 2) social attributes; and 3) usability characteristics. Face-processing skills were examined under recognition of facial expressions, identification of people by faces, and/or attention to the eyes. Social attributes were denoted by extent to which each app incorporated content from the child's everyday life (eg, people, pets, toys) and enabled participation of multiple players. Usability characteristics included playability and gamification, indexed by whether each app contained a point and reward system and whether it allowed the user to customize sounds, graphics, and avatars (refer to Table 1 for a summary of the apps).

\section{App reviews} Autimo (iOS) - Lite (free) or Upgrade fee Developer: Auticiel; age group: 6-10 years; Autimo is an app utilizing three multilevel games to help users learn the six basic facial expressions (happy, sad, angry, fearful, surprised, and disgusted). Games use both audio and text instructions, and present real pictures of the emotions. Activities include a matching expression game (Pairs), selecting the odd expression activity (Intruder), and a riddle game (Riddle). This highly customizable app allows user to add additional pictures, record their own voices, and select unique reward animations. Feedback is presented in a variety of detailed charts and graphs and automatically records time spent playing. In summary, Autimo contains unique games to practice emotional recognition skills and allows for accurate tracking of progress. 
Table I Evaluation of mobile apps with respect to social attributes, usability, and face processing

\begin{tabular}{|c|c|c|c|c|c|c|c|c|c|c|}
\hline \multirow[b]{2}{*}{ Expression } & \multicolumn{2}{|c|}{ Social attributes } & \multicolumn{5}{|l|}{ Usability } & \multicolumn{3}{|c|}{ Face processing } \\
\hline & $\begin{array}{l}\text { Encourage } \\
\text { peer } \\
\text { interaction }\end{array}$ & $\begin{array}{l}\text { Small } \\
\text { screen } \\
\text { to big } \\
\text { world }\end{array}$ & Feedback & Gamified & $\begin{array}{l}\text { Ease of } \\
\text { use }\end{array}$ & $\begin{array}{l}\text { Language } \\
\text { accessibility }\end{array}$ & $\begin{array}{l}\text { Custom } \\
\text { settings }\end{array}$ & $\begin{array}{l}\text { Identity } \\
\text { training }\end{array}$ & $\begin{array}{l}\text { Expression } \\
\text { training }\end{array}$ & $\begin{array}{l}\text { Eye } \\
\text { training }\end{array}$ \\
\hline \multicolumn{11}{|l|}{ Autimo } \\
\hline \multicolumn{11}{|l|}{ CopyMe } \\
\hline \multicolumn{11}{|c|}{$\begin{array}{l}\text { Emotions } 2 \text { from I } \\
\text { Can Do Apps }\end{array}$} \\
\hline \multicolumn{11}{|l|}{ Face Read 2} \\
\hline \multicolumn{11}{|l|}{$\begin{array}{l}\text { Faces by Whys } \\
\text { Learning }\end{array}$} \\
\hline \multicolumn{11}{|l|}{$\begin{array}{l}\text { Learning with } \\
\text { Rufus: Emotions }\end{array}$} \\
\hline \multicolumn{11}{|l|}{ Let's Learn } \\
\hline \multicolumn{11}{|c|}{$\begin{array}{l}\text { Emotions: Emotion } \\
\text { Recognition }\end{array}$} \\
\hline \multicolumn{11}{|l|}{ LOOK AT ME } \\
\hline \multicolumn{11}{|l|}{ My Memory App } \\
\hline \multicolumn{11}{|l|}{ Names to Faces } \\
\hline Training Faces & & & & & & & & & & \\
\hline
\end{tabular}

Notes: criterion met; $D$, criterion partially met; $\bigcirc$, criterion not met.

Auticiel. (2014). Autimo (Version 3.3.7) [Mobile application software]. Retrieved from: http://itunes.apple.com.

\section{CopyMe (iOS) - free}

Developer: Games Studio; age group: 9-11 years; CopyMe is a facial emotion production app employing webcam and emotion recognition software. Users produce six basic facial expressions (happy, sad, surprised, angry, fearful, and disgusted) to match a photo-prompt, and the app judges the quality of the production. If the expression is correct, feedback is given and the user progresses to the next emotion. If the emotion is not correctly made, the user can try again or skip to the next expression. Within three levels, ie, basic, medium, and hard, the user can increase the difficulty or replay easier levels. The app is moderately difficult, with the reviewers having significant difficulty producing acceptable angry and disgusted expressions. With a simple layout and use of emotion prompt pictures, the app remains accessible to pre-readers. Additional control over in-app sounds and music makes the app customizable to different sensory needs. Although challenging, CopyMe is a unique app practicing emotion production with real faces, use of one's own face, and real-time assessment.

Games Studio. (2014). CopyMe (Version 1.31) [Mobile application software]. Retrieved from: http://www.gamestudio.org/CopyMe/index.php.

\section{Emotions 2 from I Can Do Apps (iOS) - Purchase required}

Developer: I Can Do Apps, LLC; age group: 4+ years; Emotions 2 contains stock images of real people of different ages and ethnicities making various facial expressions (calm, tired, 
scared, proud, sick, excited, happy, bored, and angry). This app works on identification of different facial expressions through five levels: identifying pictures with emotions, identifying emotions with pictures, identifying pictures based on scenarios and emotions, identifying pictures with labels based on scenarios, and identifying pictures based on scenarios. Voice-over feedback and encouragement is provided. At the end of each level, limited text feedback is given.

I Can Do Apps, LLC. (2013). Emotions 2 from I Can Do Apps (Version 1.3) [Mobile application software]. Retrieved from: https://itunes.apple.com/ca/app/emotions-2-from-ican-do-apps/id661208169? mt=8.

\section{Face Read 2 (iOS) - Lite (free) or Purchase required}

Developer: ColorsKit; age group: 6-10 years; Face Read 2 uses stock photographs matched with voice-prompted emotion labels to train the recognition of six basic emotional expressions (happy, sad, angry, fearful, surprised, and disgusted). Although various achievements are awarded for completing the game, specific feedback and analysis are lacking. There is no customization or pause button within the app. Agewise, content in Face Read 2 seems geared more toward younger audiences. Although Face Read 2 uses vivid animations and a variety of subjects, content and usability are limited.

ColorsKit. (2014). Face Read 2 (Version 1.0.3) [Mobile application software]. Retrieved from: http://itunes.apple. com.

\section{Faces by Whys Learning (iOS) - Purchase required}

Developer: Whys Learning; age group: 5 years and under; Faces by Whys Learning teaches emotion labeling of illustrated faces or real faces of children, teenagers, and adults. Faces are matched with one of two labels, and voice-over allows the user to operate the app with limited reading. Expressions practiced by the app include frustrated, happy, surprised, relaxed, sad, worried, angry, thoughtful, silly, and tired. Feedback on correct and incorrect answers is given during game play, and a summary of learning is provided. However, the app does not allow the user to correct mistakes made during play. Overall, Faces by Whys Learning is simple, easy to use, and can help users practice emotion recognition skills across age groups.

Whys Learning. (2014). Faces by Whys Learning (Version 1.0) [Mobile application software]. Retrieved from: http:// www.whyslearning.com.

\section{Learning with Rufus: Emotions (iOS) - Purchase required}

Developer: Rufus Robot, Inc.; age group: 6-8 years; Learning with Rufus uses stock images of people of varied age and ethnicity using the six basic emotions (happy, sad, angry, fearful, surprised, and disgusted). The app has a very simple layout with only one correct emotion and incorrect emotion option. There is a continuous reward system that is locomotive themed. A timed doodling break is provided as reward between levels. Text feedback and encouragement are given. Although the quality of this app is medium to low, it lays out the basic emotions in a very simple context with an emphasis on casual play.

Rufus Robot, Inc. (2014). Learning with Rufus: Emotions (Version 1.0.4) [Mobile application software]. Retrieved from: http://itunes.apple.com.

\section{Let's Learn Emotions: Emotion Recognition (iOS) - Purchase required}

Developer: Everyday Speech; age group: 6+ years; Let's Learn Emotions uses both stock and uploaded images of real people making expressions from a variety of ages, ethnicities, and sex. As the user is able to add custom content, faces with any expression can be used. To teach emotion identification and understanding, users can match faces to emotion labels and use these pairings as flash cards. The discussion aspect of the app integrates an emotion with an activity, such as drawing an expression, making an expression, or utilizing an expression in some way with a friend. Text feedback is given for all the language components, and app graphics are of high quality. The integration of social environments, customizable settings, and photos makes this app educational and fun.

Everyday Speech. (2014). Let's Learn Emotions: Emotion Recognition (Version 1.2.1) [Mobile application software]. Retrieved from: https://itunes.apple.com/ca/app/lets-learnemotions-emotion/id908762349? $\mathrm{mt}=8$.

\section{LOOK AT ME (Android) - free}

Developer: Samsung; age group: 4+ years; LOOK AT ME is an eye contact and facial expression training program built around seven missions. There are four different theme choices with customizable music and voice preferences, and play is encouraged through character cards, rubies, and points. Within the game, there are activities of learning, labeling, identifying, and describing emotions as well as interactive games. These games can be played with the user's own pictures to integrate his/her social environment. Additionally, any expression can be introduced, making the app flexible and customizable. App graphics are very good 
and feedback follows immediately. Although this program is creative, customizable, and interactive for the child, the app is prone to crashes and is reportedly unable to open on certain Android devices.

Samsung LOOK AT ME (2014). LOOK AT ME (Version 3.12.20141219) [Mobile application software]. Retrieved from: https://play.google.com/store/apps/details?id=com. samsung.lookatme\&hl=en.

\section{My Memory App (iOS) - Purchase required}

Developer: Elliot Buczek, WIDTOT Software Solutions; age group: 3+ years; My Memory App allows users to take their own photos and videos to use as content in the games. Owing to the customizable nature, various facial identities and expressions can be practiced in this game. This is a card matching game that is accompanied by voice-over and text of the expressions or identities shown. Users take images or videos of people and use these images and videos as cards. Text feedback of correct pairs is shown throughout the game. The simple layout of this app makes usability easy, though an esthetic engagement is arguably lacking. The customizability of the photos/videos and reward system makes this app distinct. Adding personal photos and videos into the app extends play into peer interactions.

WIDTOT Software Solutions. (2015). My Memory App (Version 7.0) [Mobile application software]. Retrieved from: https://itunes.apple.com/us/app/my-memory-app/ $\underline{\mathrm{id} 937370829 ? \mathrm{mt}=8}$.

\section{Names to Faces (iOS) - Purchase required}

Developer: Paul Hudson; age group: 6+ years; Names to Faces integrates personalized content by having users collect own photographs of family and friends. Users then sort through their collection of faces and practice memorizing the names in each image. This app works on identity recognition, but does not provide feedback for correct or incorrect choices. It is a simple app with only camera and labeling functions. The main attraction of this app is its applicability to real life using familiar faces, in an attempt to improve the users' social environment.

Paul Hudson. (2013). Names to Faces (Version 1.0) [Mobile application software]. Retrieved from: http://itunes. apple.com.

\section{Training Faces (iOS/Android) - Purchase required}

Developer: Training With Gaming Inc.; age group: 4+ years; Training Faces features stock images of real people of different ages and ethnicities making various facial expressions (happy, excited, tired, sad, angry, confused, afraid, sick, and silly). The app works on identification of emotional expressions within a given social context story with varying difficulty levels. The app employs a train theme where the user identifies train passengers who display a given target emotion. Text feedback and encouragement are given at the end of each level. App graphics are of low-to-medium quality; however, the train theme, use of social context, and level selection make this app unique.

Training With Gaming Inc. (2012). Training Faces [Mobile application software]. Retrieved from: https://itunes. apple.com/ca/app/training-faces/id522989729?mt=8.

\section{Summary of face-processing apps}

As shown in Table 1, a wide array of mobile apps teaching face-processing skills to children on the autism spectrum is available. To follow, we summarized the main findings of our evaluation with respect to face-processing skills, social attributes, and usability characteristics.

\section{Face-processing skills}

The vast majority of apps focused on developing facial expression recognition through naming expressions (eg, Face Read 2), constructing expressions (eg, Expressions for Autism, Let's Learn Emotions), or identifying them in social scenarios (Emotions 2 and Training Faces). Two of the reviewed apps targeted the recognition of facial identity by matching personalized faces to written names (Names to Faces) or text-to-voice (My Memory App). The LOOK AT ME app was the only app directly promoting eye contact by having the player identify a small face embedded in the iris region of the eye within a larger face.

Most of the facial expression training apps supply a stock of expressive faces, and the child's task is to identify a target expression (such as a smile as happy) across different people. Some apps, not reviewed here, use avatars or cartoons to simulate expressions; however, avatars and cartoons can only approximate real facial expressions. Cartoon faces are more focused on individual parts, such as the eyes, nose, and mouth, and are void of more detailed facial features, such as lines in the corners of a person's eyes when he/she smiles. Transfer from the small screen to the big world may be limited as learning facial cues from avatars and cartoons may not improve social communication with real-life faces. Nevertheless, many apps make sure to incorporate real individuals, with faces from differing ethnicities and ages emanating a wide range of emotions. This diversity is important as children with autism have difficulties recognizing the same 
emotion across multiple individuals. ${ }^{4}$ In some apps, labeling of facial expressions was limited to the six basic emotions, such as happy, sad, angry, fearful, disgusted, and surprised, ${ }^{60}$ while other apps further built on more complex emotions such as tired and thoughtful.

Few apps involved training identity recognition and attention to eyes. In the current review, the apps addressing identity recognition presented faces in scrapbooks that the user labeled with names. Children with ASD have difficulty establishing eye contact with others and interpreting their gaze cues, skills that are essential to everyday social interactions. ${ }^{3,5,61-63}$ However, in the current review, only one app provided specific instruction to eye-gaze training, suggesting that this is a rich area of remediation for future app developers.

\section{Social attributes}

Several of the apps addressed the small screen to the big world challenge by incorporating user-generated content into the games. For example, in Autimo, LOOK AT ME, and Names to Faces, personalized photos can be featured within the app using the built-in camera functions of mobile devices. In Let's Learn Emotions, players have the capacity to upload images from a personalized photo library. A small number of the apps evaluated in this article encouraged the production of user-generated content, while the rest provided generic stock photographs. Although the majority of apps are single-player games, LOOK AT ME and Names to Faces have multiplayer modes, thereby promoting group social interactions among game players.

Another key feature for future face-training apps is the user's own production of emotional facial expressions. Production of emotions has been demonstrated to improve perceptual recognition of expressions, ${ }^{64}$ however, this important avenue for app development is certainly in its infancy. While identification of facial expressions is a key goal in current emotion learning apps, only a few focus on the actual production element. Intelligently exploiting the use of face recognition software, CopyMe is the sole app in our review, focusing on production of emotional expressions. However when evaluating CopyMe in this review, we found that some targeted expressions were almost impossible to emulate, which may act as a source of frustration for children with autism. As computerized emotion recognition technology advances, promoting facial expression production is likely to become more readily available in app programs.

\section{Usability characteristics}

The reviewed apps exhibited varying degrees of efficiency, satisfaction, and gamification. Existing face-training apps available for download varied greatly in quality and production value. Some of the apps evaluated were not always captivating games to play. Many involved repetitive, simple game elements and did not provide many challenges or incentives to continue playing. Not all apps provided real-time feedback for correct and incorrect answers. Apps should indeed provide a learning experience where users instantly make connections between their responses and expected outcomes. Users should immediately see their successes.

User testing methods were not conducted in this specific review, though future efforts would be insightful. We chose not to apply numeric user satisfaction scores to review faceprocessing apps as we did not recruit child raters. Although a detailed usability analysis of each app was beyond the scope of the current paper, applying a rigorous user testing method to assess the face-processing apps would be informative for identifying their specific strengths and weaknesses.

\section{Conclusion}

The stage is set for the development of robust next-generation face-training apps. Future developers should make use of the growing literature on gamification and serious games that promote the transfer of social skills in autism from the small screen to the big world. ${ }^{59}$ In addition to advances on the theoretical front, there are several technological advancements that face-training apps can exploit. Emotion recognition software, such as the type found in CopyMe, allows for real-time tracking of facial expressions. Automatic expression recognition software has been successfully applied for teaching children with autism spectrum how to produce more readable facial emotions. ${ }^{65}$ Automatic recognition software opens the door for facial expression training apps that link facial emotions and everyday social situations. It may also be possible to implement eye-tracking software to track eye-gaze patterns and incorporate them into new game-mechanics.

Another promising trend in mobile devices is the advance of user-generated content in which the player takes photos and videos with the device's camera and incorporates the personally authored images into the games. User-driven apps are especially powerful methods for teaching everyday faceprocessing skills where the images of people from the child's everyday life (eg, friends, siblings, teachers, parents, etc) are integrated into the intervention program. Thus, the child learns to identify a smile or angry expression of a familiar person, such as his/her mother or best friend, rather than the expression of an unfamiliar stranger. 
Now is an exciting time to be developing mobile faceprocessing apps that aim to improve social communication in autism. There is a developing literature on design principles for serious games that is readily accessible, and emerging affective computing technologies are opening the door for virtual reality applications and more robust interventions. So far, we have seen only a very small degree of this potential tapped into existing apps. We leave it to informed developers to take these theoretical and technological resources and create robust next-generation face-training apps. The resources and technologies are available; the challenge is for creative and innovative developers to put their skills to the purpose of serving the autism community. Innovative apps that succeed in following these recommendations, it is hoped, will train useful face-processing skills that make the transition from the small screen of the mobile device to the big world of everyday social life.

\section{Acknowledgment}

This work was supported by a treatment grant from Autism Speaks awarded to JWT.

\section{Disclosure}

The authors report no conflicts of interest in this work.

\section{References}

1. Baio J. Prevalence of autism spectrum disorder among children aged 8 years - autism and developmental disabilities monitoring network, 11 sites, United States, 2010. MMWR Surveill Summ. 2014;63:1-21.

2. American Psychiatric Association. Diagnostic and Statistical Manual of Mental Disorders. 5th ed. Arlington, VA: American Psychiatric Association; 2013.

3. Wolf JM, Tanaka JW, Klaiman C, et al. Specific impairment of faceprocessing abilities in children with autism spectrum disorder using the Let's Face It! skills battery. Autism Res. 2008;1:329-340.

4. Tanaka JW, Wolf JM, Klaiman C, et al. The perception and identification of facial emotions in individuals with autism spectrum disorders using the Let's Face It! Emotion Skills Battery. J Child Psychol Psychiatry. 2012;53:1259-1267.

5. Klin A, Jones W, Schultz R, Volkmar F, Cohen D. Visual fixation patterns during viewing of naturalistic social situations as predictors of social competence in individuals with autism. Arch Gen Psychiatry. 2002;59:809-816.

6. Osterling JA, Dawson G, Munson JA. Early recognition of 1-year-old infants with autism spectrum disorder versus mental retardation. Dev Psychopathol. 2002;14:239-251.

7. Volkmar F, Chawarska K, Klin A. Autism in infancy and early childhood. Anпu Rev Psychol. 2005;56:315-336.

8. Boucher J, Lewis V. Unfamiliar face recognition in relatively able autistic children. J Child Psychol Psychiatry. 1992;33:843-859.

9. Dawson G, Webb SJ, McPartland J. Understanding the nature of face processing impairment in autism: Insights from behavioral and electrophysiological studies. Dev Neuropsychol. 2005;27:403-424.

10. Weigelt S, Koldewyn K, Kanwisher N. Face identity recognition in autism spectrum disorders: a review of behavioral studies. Neurosci Biobehav Rev. 2012;36:1060-1084.

11. Celani G, Battacchi MW, Arcidiacono L. The understanding of emotional meaning of facial expressions in people with autism. JAutism Dev Disord. 1999;29:57-66.
12. Golan O, Baron-Cohen S, Golan Y. The 'reading the mind in films' task [child version]: complex emotion and mental state recognition in children with and without autism spectrum conditions. J Autism Dev Disord. 2008;38:1534-1541.

13. Gross TF. The perception of four basic emotions in human and nonhuman faces by children with autism and other developmental disabilities. J Abnorm Child Psychol. 2004;32:469-480.

14. Bedford R, Elsabbagh M, Gliga T, et al. Precursors to social and communication difficulties in infants at-risk for autism: gaze following and attentional engagement. J Autism Dev Disord. 2012;42:2208-2218.

15. Freeth M, Foulsham T, Chapman P. The influence of visual saliency on fixation patterns in individuals with autism spectrum disorders. Neuropsychologia. 2011;49:156-160.

16. Riby DM, Hancock PJB. Looking at movies and cartoons: eye-tracking evidence from Williams syndrome and autism. J Intellect Disabil Res. 2009;53:169-181.

17. Davis JM, McKone E, Dennett H, O’Connor KB, O'Kearney R, Palermo R. Individual differences in the ability to recognise facial identity are associated with social anxiety. PLoS One. 2011;6(12):e28800.

18. Baron-Cohen S, Wheelwright S, Hill J, Raste Y, Plumb I. The "reading the mind in the eyes" test revised version: a study with normal adults, and adults with Asperger syndrome or high-functioning autism. $J$ Child Psychol Psychiatry. 2001;42:241-251.

19. Halliday DWR, MacDonald SWS, Sherf SK, Tanaka JW. A reciprocal model of face recognition and autistic traits: evidence from an individual differences perspective. PLoS One. 2014;9:e94013. doi: 10.1371/journal.pone.0094013.

20. Wilson CE, Freeman P, Brock J, Burton AM, Palermo R. Facial identity recognition in the broader autism phenotype. PLoS One. 2010;5(9):1-7. doi: 10.1371/journal.pone.0012876.

21. Mundy P, Sigman M, Ungerer J, Sherman T. Defining the social deficits of autism: the contribution of non-verbal communication measures. J Child Psychol Psychiatry. 1986;27:657-669.

22. Dawson G, Toth K, Abbott R, et al. Early social attention impairments in autism: social orienting, joint attention, and attention to distress. Dev Psychol. 2004;40:271-283.

23. Warreyn P, Roeyers H, Oelbrandt T, De Groote I. What are you looking at? Joint attention and visual perspective taking in young children with autism spectrum disorder. J Dev Phys Disabil. 2005;17:55-73.

24. Droucker D, Curtin S, Vouloumanos A. Linking infant-directed speech and face preferences to language outcomes in infants at risk for autism spectrum disorder. $J$ Speech Lang Hear Res. 2013;56:567-576.

25. Eisenmajer R, Prior M, Leekam S, et al. Delayed language onset as a predictor of clinical symptoms in pervasive developmental disorders. J Autism Dev Disord. 1998;28:527-533.

26. Stagg SD, Davis R, Heaton P. Associations between language development and skin conductance responses to faces and eye gaze in children with autism spectrum disorder. J Autism Dev Disord. 2013;43:2303-2311.

27. Campbell R, Lawrence K, Mandy W, Mitra C, Jeyakuma L, Skuse D. Meanings in motion and faces: developmental associations between the processing of intention from geometrical animations and gaze detection accuracy. Dev Psychopathol. 2006;18:99-118.

28. von dem Hagen EAH, Stoyanova RS, Rowe JB, Baron-Cohen S, Calder AJ. Direct gaze elicits atypical activation of the theory-of-mind network in autism spectrum conditions. Cereb Cortex. 2014;24: 1485-1492.

29. Golan O, Baron-Cohen S. Systemizing empathy: teaching adults with Asperger syndrome or high-functioning autism to recognize complex emotions using interactive multimedia. Dev Psychopathol. 2006;18: 591-617.

30. Clarke TF, Winkielman P, McIntosh DN. Autism and the extraction of emotion from briefly presented facial expressions: stumbling at the first step of empathy. Emotion. 2008;8:803-809.

31. Carter AS, Davis NO, Klin A, Volkmar FR. Social development in autism. In: Volkmar FR, Paul R, Klin A, Cohen D, editors. Handbook of Autism and Pervasive Developmental Disorders: Vol 1. Diagnosis, Development, Neurobiology, and Behaviour. Hoboken, NJ: John Wiley \& Sons; 2005:312-334. 
32. Kasari C, Locke J, Gulsrud A, Rotheram-Fuller E. Social networks and friendships at school: comparing children with and without ASD. J Autism Dev Disord. 2011;41:533-544.

33. Williams White S, Keonig K, Scahill L. Social skills development in children with autism spectrum disorders. J Autism Dev Disord. 2007;37:1858-1868

34. Bauminger N, Kasari C. Loneliness and friendship in high-functioning children with autism. Child Dev. 2000;71:447-456.

35. Cappadocia MC, Weiss JA, Pepler D. Bullying experiences among children and youth with autism spectrum disorders. J Autism Dev Disord. 2011;42:266-277.

36. Humphrey N, Lewis S. Make me normal: the views and experiences of pupils on the autistic spectrum in mainstream secondary schools. Autism. 2008;12:23-46.

37. Locke J, Rotheram-Fuller E, Kasari C. Exploring the social impact of being a typical peer model for included children with autism spectrum disorder. J Autism Dev Disord. 2012;42:1895-1905.

38. Szatmari P, Bartolucci G, Bremmer R. Asperger's syndrome and autism: comparison of early history and outcome. Dev Med Child Neurol. 1989;31:709-720.

39. Venter A, Lord C, Schopler E. A follow-up study of high-functioning autistic children. J Child Psychol Psychiatry. 1992;33:489-507.

40. Simone R. Asperger's on the Job. Arlington, TX: Future Horizons; 2010.

41. Rao PA, Beidel DC, Murray MJ. Social skills interventions for children with Asperger's syndrome or high functioning autism: a review and recommendations. J Autism Dev Disord. 2008;38:353-361.

42. Schultz RT. Developmental deficits in social perception in autism: the role of the amygdala and fusiform face area. Int J Dev Neurosci. 2005;23:125-141.

43. Sasson NJ. The development of face processing in autism. J Autism Dev Disord. 2006;36:381-394.

44. Faja S, Aylward E, Bernier R, Dawson G. Becoming a face expert: a computerized face-training program for high-functioning individuals with autism spectrum disorders. Dev Neuropsychol. 2007;33:1-24.

45. Rice LM, Wall CA, Fogel A, Shic F. Computer-assisted face processing instruction improves emotion recognition, mentalizing, and social skills in students with ASD. J Autism Dev Disord. 2015:1-11.

46. Tanaka JW, Wolf JM, Klaiman C, et al. Using computerized games to teach face recognition skills to children with autism spectrum disorder: the Let's Face It! program. J Child Psychol Psychiatry. 2010;51: 944-952.

47. Hopkins IM, Gower MW, Perez TA, et al. Avatar assistant: improving social skills in students with an ASD through a computer-based intervention. J Autism Dev Disord. 2011;41:1543-1555.

48. Pea R, Nass C, Meheula L, et al. Media use, face-to-face communication, media multitasking, and social well-being among 8-to 12-year-old girls. Dev Psychol. 2012;48:327-336.

49. Fager J. Autism and the iPAD [60 Minutes]. New York: CBS; 2011.

50. Althaus M, de Sonneville LM, Minderaa RB, Hensen LG, Til RB. Information processing and aspects of visual attention in children with the DSM-III-R diagnosis "Pervasive Developmental Disorder Not Otherwise Specified" (PDDNOS): II. Sustained attention. Child Neuropsychol. 1996;2:17-29.
51. Nally B, Houlton B, Ralph S. The management of television and video by parents of children with autism. Autism. 2000;4:331-337.

52. Shane HC, Albert PD. Electronic screen media for persons with autism spectrum disorders: results of a survey. J Autism Dev Disord. 2008;38:1499-1508.

53. Yee HSS. Mobile technology for children with autism spectrum disorder: major trends and issues. IEEE Symposium on E-learning, E-Management and E-Services. Washington, DC: IEEE; 2012:1-5.

54. Rose D, Meyer A. Teaching Every Student in the Digital Age: Universal Design for Learning. Alexandria, VA: ASCD; 2002.

55. International Standards Organization. ISO 9241-11: Ergonomic Requirements for Office Work with Visual Display Terminals (VDTs) s-Part II: Guidance on Usability. Geneva: International Standards Organization; 1998.

56. Nielsen J, Molich R. Heuristic evaluation of user interfaces. Paper presented at: Proc. ACM CHI'90 Conf; April 1-5, 1990:249-256. Seattle, WA.

57. Deterding S, Dixon D, Khaled R, Nacke L. From game design elements to gamefulness: defining "gamification". Paper presented at: MindTrek '11 Proceedings of the 15th International Academic MindTrek Conference: Envisioning Future Media Environments. New York, NY: ACM; 2011:9-15.

58. Hamari J, Koivisto J, Sarsa H. Does gamification work? - A literature review of empirical studies on gamification. Paper presented at: "9241-11 Ergonomic Requirements for Office Work with Visual Display Terminals (VDTs)-Part II Guidance on Usability”; 2014: 3025-3034; Washington, DC. [ISO/IEC 9241-11, 1998 (E)].

59. Whyte EM, Smyth JM, Scherf KS. Designing serious game interventions for individuals with autism. J Autism Dev Disord. 2014;1-12.

60. Ekman P, Friesen W. Constants across cultures in the face and emotion. J Pers Soc Psychol. 1971;17:124-129.

61. Joseph RM, Tanaka J. Holistic and part-based face recognition in children with autism. J Child Psychol Psychiatry. 2003;44:529-542.

62. Tanaka JW, Sung AN. The "Eye Avoidance" hypothesis of face processing in autism. J Autism Dev Disord. 2013:1-15.

63. Xu, B, Tanaka, JW. Teaching children with autism to recognize faces In Patel V, Preedy V, Martin C, editors. Comprehensive guide to autism. New York: Springer; 2014:1043-1059.

64. Deriso D, Susskind J, Tanaka J, et al. Exploring the facial expression perception-production link using real-time automated facial expression recognition. In: Fitzgibbon A, Lazebnik S, Sato Y, Schmid C, editors. Lecture Notes in Computer Science: European Conference on Computer Vision, Workshop on What's in a Face. Berlin, Heidelberg: Springer; 2012:270-279.

65. Gordon I, Bartlett M, Pierce MS, Tanaka JW. Training voluntary facial expressions using automated, real-time feedback. J Autism Dev Disord. 2014;44:2486-2498
Advanced Health Care Technologies

\section{Publish your work in this journal}

Advanced Health Care Technologies is an international, peer reviewed, open access journal that provides a unique forum for articles on: point-of-care, health care diagnostics and treatment, bioengineering, biotechnology, biosensing, electronics, clinical/medical science, chemical engineering, materials science, regenerative medicine, micro-/

\section{Dovepress}

nano-technologies, and methods and applications for nanoscience and nanotechnology. The manuscript management system is completely online and includes a very quick and fair peer review system, which is all easy to use. Visit http://www.dovepress.com/testimonials.php to read real quotes from published authors. 